\title{
Teaching Instrumental Analytical Chemistry during COVID-19 Times in a Developing Country: Asynchronous versus Synchronous Communication
}

\author{
María Emilia Villanueva,* Emiliano Camilli, Ana Clara Chirillano, Juan Angel Cufré, \\ Maria Cristina de Landeta, Laura Natalia Rigacci, Viviana Miriam Velazco, and Andrés Fabián Pighin
}

Cite This: https://dx.doi.org/10.1021/acs.jchemed.0c00664

Read Online

\section{ACCESS $1 \quad$ Wlll Metrics \& More 回 Article Recommendations}

ABSTRACT: On Mar. 19, 2020, Argentina's government decided to close academic institutions for an indefinite time in an attempt to contain the spread of the COVID-19 pandemic. Since the University established that, when the quarantine ends, 5 weeks will be reserved for face-to-face activities that could not be carried out virtually (laboratory lessons and final exams), the main focus on the online activities was in the theoretical lessons. For the Instrumental Analytical Chemistry course both synchronous strategy such as questions and answer sessions and asynchronous communication such as Microsoft PowerPoint presentations with explicative audios, simulated assays, and assignments were adopted. A survey conducted with our students indicated that although synchronous lessons provided face-to-face interaction, the lack of good Internet connectivity was the main weakness of this strategy. On the other hand, asynchronous lessons did not require very high bandwidth networks and had the possibility of stopping the lesson and

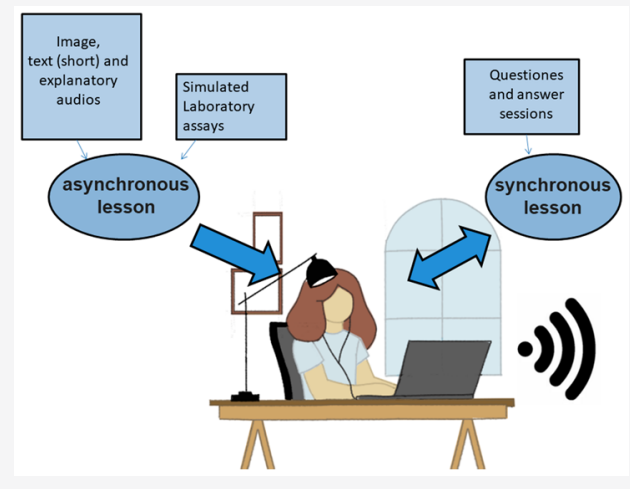
continuing it later. However, students' lack of interaction with their teachers was the main drawback of this type of communication. Most of the students pointed out that a blend of synchronous and asynchronous communication is more desirable for Instrumental Analytical Chemistry lessons than asynchronous or synchronous communication separately.

KEYWORDS: Upper-Division Undergraduate, Analytical Chemistry, Distance Learning/Self Instruction, Internet/Web-Based Learning, Computer-Based Learning

\section{INTRODUCTION}

Instrumental Analytical Chemistry course is dictated for Food Engineering students, and it corresponds to the fifth semester of the aforementioned degree. In a typical class the number of students is around 20; this year it has been 15 . The prerequisite courses for enrolling in this course are Analytical Chemistry and Physics. All students come to the class with the same background. The course consists of theoretical and laboratory lessons, and it meets $6 \mathrm{~h}$ per week $(3 \mathrm{~h}$ are devoted to theoretical activities and $3 \mathrm{~h}$ to practical activities). The covered topics in the lessons are Sample Preparation; Basic Principles of Spectroscopy; Ultraviolet, Visible, and Fluorescence Spectroscopy; Atomic Absorption Spectroscopy; Atomic Emission Spectroscopy; High-Performance Liquid Chromatography; Gas Chromatography; Conductometry; and Potentiometry.

During the past few months, we have been living an experience that has accelerated the changes in our lives to a position that would be impossible to imagine 6 months ago. The transition to virtual environments that has been taking place slowly and gradually over the past 20 years in our University has suddenly been struck overnight by a new scenario: everyone at home.

On Mar. 19, 2020, Argentina's government decided to close academic institutions for an indefinite time in an attempt to contain the spread of the COVID-19 pandemic. This new situation affected our teaching and learning scenario from night to day. Since classes had started a week before, the University authorities established that academic activities should continue virtually until the quarantine ends. After that, 5 weeks will be reserved for face-to-face activities that could not be carried out virtually (laboratory lessons and final exams). The experiments that will be carried out are detailed in Table 1.

Special Issue: Insights Gained While Teaching Chem-

istry in the Time of COVID-19

Received: June 15, 2020

Revised: July 30, 2020 
Table 1. Laboratory Lessons That Will Be Dictated after the Quarantine Ends

\begin{tabular}{|c|c|c|}
\hline Analyte & Sample & Method \\
\hline Phosphorus & Milk & UV-vis spectroscopy \\
\hline Calcium & Milk & $\begin{array}{l}\text { Atomic absorption } \\
\text { spectroscopy }\end{array}$ \\
\hline Sodium and potassium & Milk & $\begin{array}{l}\text { Atomic emission } \\
\text { spectroscopy }\end{array}$ \\
\hline Phosphoric acid & Water & Potentiometric titration \\
\hline Formic and acetic acid & Water & Conductimetric titration \\
\hline Xylene, toluene, and benzene & Water & Gaseous chromatography \\
\hline Vitamin C & $\begin{array}{l}\text { Orange } \\
\text { juice }\end{array}$ & $\begin{array}{l}\text { High pressure liquid } \\
\text { chromatography }\end{array}$ \\
\hline
\end{tabular}

In Argentina, the National Universities are financed by the Ministry of Education and are free of charge for everyone. As a consequence, the students that attend our University are from different socioeconomic environments, with different accessibility to the Internet. Therefore, one of the main challenges in the implementation of the virtual lessons was to develop a system that would not increase these inequalities.

Online learning environments can be divided into a triad of synchronous, asynchronous, and a combination of both. ${ }^{1}$ Synchronous communication can be defined as a dialogue that proceeds under conditions of simultaneous presence in a shared communicative space, which may be physical or virtual. This definition includes video and audio conferencing as well as face-to-face activities. ${ }^{2}$ Synchronous learning environments provide real-time interaction, which can be collaborative, incorporating activities such as an instructor's lecture with a questions-answer session. ${ }^{3}$ However, a synchronous session requires simultaneous student and teacher presence and access to good Internet connectivity. Asynchronous communication, on the other hand, arises when interlocutors do not simultaneously share the communicative space, as in email or postal correspondence. Asynchronous environments are not time bound, and students can work on the proposed activities at their own pace, being in a more individualized and unsupervised learning space. ${ }^{4}$ A hybrid system mixes synchronous and asynchronous activities.

During this semester we adopted both synchronous and asynchronous strategies. Since all of the students were enrolled in the learning management system, we communicated through it. The obligatory lessons were asynchronous, taking into account that they do not require a very high bandwidth. They included Microsoft PowerPoint presentations with explicative audio and assignments. The assignments were exercises and questions that were based on real case studies or in virtual simulators of the instrumental analytical methods. The doubts that arose were answered by private messages from the instructors or in synchronous question and answer sessions. The midterm exams were carried out virtually, sending students the exam that should be sent back $3 \mathrm{~h}$ later. The final exams will be carried out when the quarantine ends.

\section{ASYNCRONOUS COMMUNICATION}

\section{Microsoft PowerPoint Presentations with Explicative Audios}

Microsoft PowerPoint was the chosen software to prepare the presentations. They were designed so that they did not contain a large amount of text, focusing on images. Research shows that audiences have difficulty simultaneously processing presented written and verbal information, so the more words on the slide, the less the students would understand. ${ }^{5,6}$ The slides were complemented with audio explaining the concepts recreating the lessons that we would have had if the quarantine had not been established. However, premade online lessons were highly structured and allowed no variation, while in faceto-face lessons discussions and questions often led to better understanding by the students. Students were also recommended to read the bibliography.

Students could communicate with the teachers by email, but they did not receive immediate feedback or benefit from listening to other students' questions and comments. It was proposed that transactional distance is likely to be lessened through the use of highly interactive mediums, such as phone calls and class discussions, rather than less interactive mediums, such as video recordings or written lessons. ${ }^{7}$ As a consequence, we incorporated synchronic question and answer sessions.

\section{Simulated Aassays}

Despite the fact that the traditional laboratory experimentation is irreplaceable, ${ }^{8}$ the virtual learning simulation laboratories are an alternative where students' learning can be enhanced through the use of simulations. These softwares have been used extensively in science education to create sophisticated virtual laboratories in which students can learn science by experimentation, visualize abstract concepts, and create mental representations which promote long-term memory. ${ }^{9-12}$

Simulations are interactive digital learning environments that imitate a real-life process or situation. ${ }^{13,14}$ Virtual simulation laboratories employ the use of software to reproduce and imitate real physical and chemical processes that are investigated in a traditional laboratory.

UV-vis and fluorescence spectrophotometry simulators were used. The simulators were available online, and they were free of charge. For UV-vis spectrophotometry, the software was designed by Gary L. Bertrand from University of Missouri. ${ }^{15}$ For fluorescence spectrophotometry FluSpect ver. 1.0 was used. ${ }^{16}$ An activity guide was sent to instruct the students in the learning process. Students were, therefore, able to see, manipulate, interrogate, and discuss science concepts during simulation laboratory sessions. As it was mentioned before, the laboratory experimentation lessons are still going to be taught when the quarantine ends. Nevertheless, the simulated laboratory sessions were included with the purpose of enhancing students' engagement and interest in learning.

\section{Assignments}

In order to evaluate the students' progress, an assignment was sent for each dictated topic. These assignments included questions about the activities performed using the previously mentioned simulators and about case studies. All of the students completed the tasks on time. They used email communication to solve their doubts. These activities were corrected by the instructors, and the mistakes were clarified individually.

\section{SYNCRONOUS COMMUNICATION}

\section{Questions and Answer Sessions}

Once a week, question and answer sessions were carried out. The assistance was not mandatory. Hence, not all of the students were present, generally from 6 to 9 students. According to literature, dialogue between students and the 
teacher and between students is more likely to occur in synchronous courses because they are able to ask questions, receive immediate feedback, and interact in real-time discussions during synchronous class sessions. ${ }^{2}$ However, in our case, the communication was not as effective as we thought it would be. The students did not turn their camera or mic on. They generally used the chat or chose one of the students to ask for questions. Some of them had bad Internet connectivity, which made the communication more difficult. The amount of dialogue in an online course is determined by many factors, including the personalities of both the instructor and students, the subject matter being taught, the number of students, and the types of communication used. ${ }^{7,17}$ In order to improve the dialogue with students, they were asked individually if they had any doubts. This forced them to turn their mic on to answer the direct question that had been made, and they started to interact more. Although they did not interact as much as expected during the question and answer sessions, they reported that they found this kind of communication useful to solve doubts.

\section{STUDENTS' FEEDBACK}

In order to have a more objective vision of how students better understand the explanations provided, we conducted a survey with closed-ended questions at the end of the semester to ask for students' perceptions of this educational experience. Twelve students participated in a voluntary online survey in which they were asked to opine about the course in several aspects. Unfortunately, the approval of the University ethics board could not be obtained. Nevertheless, the results are broadly summarized in the following paragraphs.

Students reported their appreciation for the pre-made online lessons, pointing out that the Microsoft PowerPoint presentations' audio could be stopped and repeated as many times as needed and they had time to reflect about the discussed topics. They also expressed that the ability to send private messages to both the instructor and to other students in the course was useful. However, they disliked the lack of interaction and some of them revealed that they had software issues. For example, some of the students could not hear the explicative audio in the presentations, so we provided them separately. On the other hand, immediate feedback during synchronous sessions was the main reported advantage. Most students mentioned that a lack of good connectivity was an important disadvantage in synchronous lessons since the limitations of existing network technologies decreased the quality of symmetrical real-time interaction in online learning environments. As it was described previously, Internet connectivity was an issue that was taken into account when designing the learning strategy and asynchronous activities did not require very high bandwidth networks. When the students were asked about the best way to understand the topics in this course, most of them preferred a combination of asynchronous lessons with synchronous question and answer sessions. It should be pointed out that although the number of students that participated of this survey was low, the course had 15 students in total, meaning that most of them participated.

\section{CONCLUSIONS}

The findings of the study indicate that a blend of synchronous and asynchronous modes is more desirable for Instrumental Analytical Chemistry learners of National University of Luján.
Although synchronous lessons were provided with face-to-face interaction, the lack of good Internet connectivity was the main weakness of this strategy. On the other hand, asynchronous lessons did not require very high bandwidth networks and had the possibility of stopping the lesson and continuing it later. However, the students' lack of interaction with their teachers was the main drawback of this type of communication.

In the asynchronous mode, students could construct their knowledge by carefully thinking and analyzing. Synchronous sessions added the pressure to understand immediately, and it was difficult to monitor if they were understanding because they did not participate as much as required. Besides, the lack of good connectivity diminished the assistance and the permanence of the students in the sessions. Therefore, the combination of synchronous and asynchronous activities would be the best way to impart knowledge in our subject.

\section{AUTHOR INFORMATION}

\section{Corresponding Author}

María Emilia Villanueva - Departamento de Ciencias Básicas, Universidad Nacional de Luján (UNLu), Buenos Aires 6700, Argentina; Instituto de Química y Metabolismo del Fármaco (IQUIMEFA), CONICET-Universidad de Buenos Aires (UBA), Buenos Aires C1033AAJ, Argentina; 이이이.org/ 0000-0002-9986-660X; Email: mevillanueva@conicet.gov.ar

\section{Authors}

Emiliano Camilli - Departamento de Ciencias Básicas, Universidad Nacional de Luján (UNLu), Buenos Aires 6700, Argentina

Ana Clara Chirillano - Departamento de Ciencias Básicas, Universidad Nacional de Luján (UNLu), Buenos Aires 6700, Argentina

Juan Angel Cufré - Departamento de Ciencias Básicas, Universidad Nacional de Luján (UNLu), Buenos Aires 6700, Argentina

Maria Cristina de Landeta - Departamento de Ciencias Básicas, Universidad Nacional de Luján (UNLu), Buenos Aires 6700, Argentina

Laura Natalia Rigacci - Departamento de Ciencias Básicas, Universidad Nacional de Luján (UNLu), Buenos Aires 6700, Argentina

Viviana Miriam Velazco - Departamento de Ciencias Básicas, Universidad Nacional de Luján (UNLu), Buenos Aires 6700, Argentina

Andrés Fabián Pighin - Departamento de Ciencias Básicas, Universidad Nacional de Luján (UNLu), Buenos Aires 6700, Argentina

Complete contact information is available at:

https://pubs.acs.org/10.1021/acs.jchemed.0c00664

\section{Notes}

The authors declare no competing financial interest.

\section{ACKNOWLEDGMENTS}

We thank our students for having participated in the survey.

\section{REFERENCES}

(1) Perveen, A. Synchronous and Asynchronous E-Language Learning: A Case Study of Virtual University of Pakistan. Open Prax. 2016, 8 (1), 21-39. 
(2) O’Rourke, B.; Stickler, U. Synchronous Communication Technologies for Language Learning: Promise and Challenges in Research and Pedagogy. Lang. Learn. High. Educ. 2017, 7 (1), 1-20.

(3) Salmon, G. E-Tivities: The Key to Active Online Learning; Routledge, 2013.

(4) Casselman, M. D.; Atit, K.; Henbest, G.; Guregyan, C.; Mortezaei, K.; Eichler, J. F. Dissecting the Flipped Classroom: Using a Randomized Controlled Trial Experiment to Determine When Student Learning Occurs. J. Chem. Educ. 2020, 97 (1), 27-35.

(5) Pate, A.; Posey, S. Effects of Applying Multimedia Design Principles in PowerPoint Lecture Redesign. Curr. Pharm. Teach. Learn. 2016, 8 (2), 235-239.

(6) Issa, N.; Schuller, M.; Santacaterina, S.; Shapiro, M.; Wang, E.; Mayer, R. E.; DaRosa, D. A. Applying Multimedia Design Principles Enhances Learning in Medical Education. Med. Educ. 2011, 45 (8), 818-826.

(7) Moore, M. G. Theory of Transactional Distance. Theor. Princ. Distance Educ. 1993, 1, 22-38.

(8) Bretz, S. L. Evidence for the Importance of Laboratory Courses. J. Chem. Educ. 2019, 96 (2), 193-195.

(9) Tüysüz, C. The Effect of the Virtual Laboratory on Students' Achievement and Attitude in Chemistry. Int. Online J. Educ. Sci. 2010, 2 (1), 37-53.

(10) Dalgarno, B.; Bishop, A. G.; Adlong, W.; Bedgood, D. R., Jr Effectiveness of a Virtual Laboratory as a Preparatory Resource for Distance Education Chemistry Students. Comput. Educ. 2009, 53 (3), 853-865.

(11) Tatli, Z.; Ayas, A. Virtual Laboratory Applications in Chemistry Education. Procedia-Soc. Behav. Sci. 2010, 9, 938-942.

(12) Ullah, S.; Ali, N.; Rahman, S. U. The Effect of Procedural Guidance on Students' Skill Enhancement in a Virtual Chemistry Laboratory. J. Chem. Educ. 2016, 93 (12), 2018-2025.

(13) Makransky, G.; Terkildsen, T. S.; Mayer, R. E. Adding Immersive Virtual Reality to a Science Lab Simulation Causes More Presence but Less Learning. Learn. Instr. 2019, 60, 225-236.

(14) Shalliker, R. A.; Kayillo, S.; Dennis, G. R. Optimizing Chromatographic Separation: An Experiment Using an HPLC Simulator. J. Chem. Educ. 2008, 85 (9), 1265.

(15) Bertrand, G. L. Spectrophotometry, a simulated experiment; University of Missouri-Rolla, Rolla, MO, USA, 2002; http://web. mst.edu/ gbert/Color_Lg/color.html?455 (accessed on June 10, 2020).

(16) Bigger, S. W.; Bigger, A. S.; Ghiggino, K. P. FluSpec: A Simulated Experiment in Fluorescence Spectroscopy. J. Chem. Educ. 2014, 91 (7), 1081-1083.

(17) Christiansen, M. A.; Nadelson, L.; Etchberger, L.; Cuch, M.; Kingsford, T. A.; Woodward, L. O. Flipped Learning in Synchronously-Delivered, Geographically-Dispersed General Chemistry Classrooms. J. Chem. Educ. 2017, 94 (5), 662-667. 